\title{
IMPACTOS DO NCPC AOS EMBARGOS À EXECUÇÃO FISCAL
}

\author{
Gabriela Silva de Lemos
}

\section{INTRODUÇÃO}

O Novo Código de Processo Civil (NCPC), introduzido pela Lei n. 13.105/2015, trouxe inúmeras inovações ao direito processual civil e tem, a nosso ver, o propósito de adequar o procedimento judicial às diretrizes constitucionais, já que o Código de Processo Civil de 1973 (CPC/73) reclamava premissas adequadas aos princípios da Constituição Federal (CF) promulgada em 1988. Essa conclusão decorre já do art. $1^{\circ}$ do NCPC que determina que "o processo civil será ordenado, disciplinado e interpretado conforme os valores e as normas fundamentais estabelecidos na Constituição da República Federativa do Brasil, observando-se as disposições deste Código".

Com efeito, sendo a CF a base para a aplicação das demais normas, evidentemente as regras do processo civil estabelecidas seja na lei geral (NCPC), seja em leis especiais (Lei de Execução Fiscal, Lei do Mandado de Segurança, Lei da Medida Cautelar Fiscal, dentre outras) somente podem ser aplicadas em conformidade com as normas e os valores fundamentais, quais sejam: segurança jurídica, contraditório, ampla defesa, dentre outros que asseguram os direitos de todos os cidadãos.

Considerando os diversos regramentos aplicáveis ao processo civil, analisaremos no presente estudo os impactos do NCPC ao rito processual das execuções fiscais, em especial o processamento dos embargos às execuções fiscais. Atendo-se, assim, ao objeto do presente estudo, devemos iniciá-lo relembrando que o 
procedimento aplicável às execuções fiscais é definido pela Lei n. 6.830/1980 (Lei da Execução Fiscal - LEF), lei especial que, em princípio, não poderia ser revogada pelo NCPC, lei geral sobre a matéria.

Nesse contexto, analisaremos a seguir a compatibilidade entre o NCPC e a LEF, observando sua adequação ao texto constitucional e exemplificando as relevantes mudanças práticas que poderão ser observadas no rito dos embargos de devedor, em razão do advento do NCPC.

\section{APLICAÇÃO SUBSIDIÁRIA DO NCPC AO RITO DAS EXECUÇÕES FISCAIS}

A LEF, em seu art. $1^{\circ}$, estabelece que "A execução judicial para cobrança da Dívida Ativa da União, dos Estados, do Distrito Federal, dos Municípios e respectivas autarquias será regida por esta Lei e, subsidiariamente, pelo Código de Processo Civil" (grifo nosso). O NCPC, por sua vez, também deixa claro em seu art. 318 que "Aplica-se a todas as causas o procedimento comum, salvo disposição em contrário deste Código ou de lei. Parágrafo único. O procedimento comum aplica-se subsidiariamente aos demais procedimentos especiais e ao processo de execução" (grifos nossos). Fica claro, assim, que as disposições contidas no NCPC são aplicáveis subsidiariamente às execuções fiscais e, evidentemente, aos respectivos embargos de devedor.

Por aplicação subsidiária entende-se a utilização complementar de dispositivos da lei geral (NCPC) às lacunas da lei especial (LEF), desde que não sejam contraditórios. Nessa linha, o Superior Tribunal de Justiça (STJ) tem entendimento consolidado, como vemos no disposto no Recurso Especial (REsp) n. 1390431, no sentido de que "Nos termos do art. $1^{\circ}$ da Lei n. 6.830/80, as disposições contidas no Código de Processo Civil aplicam-se à execução fiscal apenas de modo subsidiário, ou seja, somente quando naquela norma (a LEF) não houver disposição sobre o que se quer disciplinar" (REsp n. 1390431/PE, Rel. Min. Eliana Calmon, $2^{\text {a }}$ Turma, julgado em: 17 out. 2013, DJe: 24 out. 2013).

Em julgamento na sistemática dos recursos repetitivos, decidiu aquela corte, em outra oportunidade, que a aplicabilidade do NCPC estaria condicionada à compatibilidade entre as normas:

Não coaduno com o raciocínio de que as reformas feitas no CPC/73 pela Lei n. 11.382/2006 sejam um "pacote fechado" que deve ser integralmente aplicado às execuções fiscais. De ver que a própria exposição de motivos desta 
reconhece a "relativa autonomia" do executivo fiscal com a Lei n. 6.830/80. Sendo assim, em obediência aos princípios orientadores de ambas as leis, é necessário confrontar norma com norma para verificar aquelas que são compatíveis com a LEF e com os princípios de sua elaboração, notadamente, a valorização da cobrança do crédito público sobre o privado. [...] Em outra ponta, sempre com respeito aos que pensam de forma diversa, é de se afastar a aplicação nas execuções fiscais do art. 736, do CPC, na redação dada pela Lei n. 11.382/2006, que exime o executado de garantir o juízo para opor-se à execução por meio de embargos. Isto porque a LEF não é silente no ponto, pois seu art. $16, \$ \mathbb{1}^{\circ}$ registra expressamente que "Não são admissíveis embargos do executado antes de garantida a execução". (REsp n. 1272827/PE, Rel. Min. Mauro Campbell Marques, 1ª Seção, julgado em: 22 maio 2013, DJe: 31 maio 2013)

Há situações, assim, em que a jurisprudência se sedimentou pela aplicação da regra prevista na lei geral, como no caso da aplicação do art. 739-A do CPC/73, com redação dada pela Lei n. 11.382/2006, quanto à necessidade de atribuição de efeito suspensivo aos embargos de devedor pelo juízo, afastando-se o entendimento de que o efeito suspensivo automático dos embargos de devedor seria a lógica prevista expressamente na LEF. Por outro lado, há também situações em que se afastou a aplicação da regra geral (art. 736 do CPC/73, com redação dada pela Lei n. 11.382/2006), que previa o cabimento de embargos de devedor antes de garantido o juízo, por se entender que tal regra contrariaria o art. $16, \sqrt{ } 1^{\circ}$, da lei especial (LEF).

Ainda no contexto da aplicação do NCPC ao rito das execuções fiscais, vale mencionar o art. 15, que estabelece de forma ainda mais ampla que, "na ausência de normas que regulem processos eleitorais, trabalhistas ou administrativos, as disposições deste Código lhes serão aplicadas supletiva e subsidiariamente”.

Hugo de Brito Machado Segundo e Raquel Cavalcanti Ramos Machado ${ }^{1}$ entendem que o art. 15 do NCPC é

mera explicitação didática, enunciando algo que em larga medida já vinha sendo feito à luz do CPC de 1973. Em verdade, essa aplicação supletiva e subsidiária

1 MACHADO SEGUNDO, Hugo de Brito; MACHADO, Raquel Cavalcanti Ramos. O novo Código de Processo Civil e o Processo Tributário. In: ROCHA, Valdir de Olveira (Coord.). Grandes questões atuais do direito tributário. São Paulo: Dialética, 2015. v. 19. 
é explicada pela Teoria do Direito, e decorre do fato de que se estaria diante de situações análogas, dotadas e um mesmo "elemento relevante", sendo contrário aos valores consagrados no próprio sistema deixar uma delas sem tratamento específico, pois isso implicaria sujeita-la à norma geral segundo a qual a fata de previsão implica impossibilidade de se praticar o ato.

O termo acrescido nesse dispositivo, aplicação supletiva, transmite a ideia de complementação. Em outras palavras, a aplicação supletiva da admite que, mesmo havendo apenas uma lacuna parcial na norma especial (eleitoral, trabalhista ou administrativa), a regra prevista no NCPC pode ser aplicada para complementá-la. Assim, diante da existência de abrangências distintas do NCPC (art. 15 e 318) a procedimentos especiais, parece-nos importante avaliar como será a sua aplicação ao rito das execuções fiscais, já que é esse o objeto de nosso estudo.

Pois bem, a aplicação subsidiária (prevista para o rito das execuções fiscais e também para os procedimentos trabalhista, eleitoral e administrativo) indica a aplicação da regra geral às situações em que houver uma lacuna na lei especial. Por sua vez, a aplicação supletiva (prevista apenas para os procedimentos trabalhista, eleitoral e administrativo) indica a possibilidade de complementação normativa, isto é, a aplicação de uma norma mais completa quando houver uma lacuna parcial na legislação especial. Com isso, considerando que a aplicação do NCPC ao rito da execução fiscal é apenas subsidiária, seus dispositivos somente poderão ser observados se houver lacuna completa na LEF.

Em outras palavras, em situações em que a LEF estabelece regra parcial ou incompleta, não é possível que dispositivo mais completo previsto pelo NCPC seja aplicado ao rito das execuções fiscais. Aliás, não é demais relembrar que a própria LEF estabelece que a aplicação do NCPC seja apenas subsidiária. Daí porque admitir que o NCPC poderia ser aplicado também supletivamente, alterando conceitos e regras preexistentes, seria o mesmo que admitir a possibilidade de lei geral revogar lei especial, o que não é possível em nosso sistema jurídico.

Fixadas tais premissas, adiante trataremos das mudanças práticas no rito e no procedimento dos embargos de devedor decorrentes do advento do NCPC.

\section{RELEVANTES ALTERAÇÕES NO PROCEDIMENTO}

Partindo-se da premissa que os dispositivos do NCPC são aplicáveis apenas subsidiariamente ao rito das execuções fiscais, discutiremos os relevantes impactos trazidos por esse diploma ao procedimento dos embargos às execuções fiscais. 


\subsection{Prazos aplicáveis}

Com o advento do art. 219 do NCPC, os prazos processuais passaram a ser computados considerando-se apenas os dias úteis. A LEF, por sua vez, nada dispõe acerca da forma de contagem dos prazos para adoção dos atos processuais nela previstos, sendo que a legislação que estabelecia, até o advento do NCPC, que os prazos deveriam ser computados de forma contínua era o hoje revogado art. 178 do CPC/73.

Com isso, se desde a edição da LEF o CPC/73 já era aplicado subsidiariamente para definir a forma de contagem dos prazos processuais, da mesma forma, com a alteração da regra processual, o NCPC deve ser observado subsidiariamente nesse particular. Assim, a nosso ver, no âmbito das execuções fiscais e dos respectivos embargos, os prazos devem ser computados apenas considerando-se os dias úteis.

\subsection{Efeito suspensivo dos embargos à execução fiscal}

Desde o advento da Lei n. 11.382/2006, que incluiu o art. 739-A no CPC/73, muito se discute sobre a atribuição de efeito suspensivo aos embargos à execução fiscal, que tem o condão de evitar o prosseguimento da execução fiscal embargada. Isso pois o CPC/73 passou a prever que os embargos à execução não tinham efeito suspensivo automático, mas este poderia ser conferido pelo juízo, a pedido do embargante, se "relevantes seus fundamentos, o prosseguimento da execução manifestamente possa causar ao executado grave dano de difícil ou incerta reparação, e desde que a execução já esteja garantida por penhora, depósito ou caução suficientes”.

Em princípio, dada a aplicação exclusivamente subsidiária e não supletiva da regra geral (NCPC) à lei de execução fiscal, não vislumbramos como poderia tal dispositivo impactar o rito das execuções fiscais. Deveras, é da ordem lógica de atos processuais estabelecidos nos art. 18 e 19 da LEF que decorre o efeito suspensivo dos embargos de devedor, uma vez que não é possível dar movimentação à execução fiscal até que sejam encerradas todas as fases previstas pela lei. Logo, trata-se de verdadeira situação em que a norma especial (LEF) contém lacuna parcial, já que, apesar de não prever expressamente o efeito suspensivo dos embargos de devedor, induz a atribuição de efeito suspensivo a esse incidente. De fato, não havendo uma lacuna completa, não poderia ser a lei especial supletivamente integrada por regra prevista em lei geral (NCPC). 
A despeito desse entendimento pessoal, a jurisprudência inclinou-se pela aplicação do art. 739-A ao rito das execuções fiscais, daí porque admitiremos a aplicação do art. 919 do NCPC, que àquele substituiu, ao procedimento ora em análise. Com efeito, o art. 919 do NCPC manteve como regra geral a não atribuição automática de efeito suspensivo aos embargos à execução e passou a estabelecer que para seu deferimento (i) devem ser observados os requisitos para a concessão da tutela provisória e (ii) a execução já esteja garantida por penhora, depósito ou caução suficientes.

Ocorre que não foi definido nesse dispositivo se os requisitos seriam aqueles para a concessão da tutela provisória de urgência ou para a tutela provisória da evidência. A tutela de urgência "será concedida quando houver elementos que evidenciem a probabilidade do direito e o perigo de dano ou o risco ao resultado útil do processo", conforme dispõe o art. 300 do NCPC. Já a tutela de evidência será concedida "independentemente da demonstração de perigo de dano ou de risco ao resultado útil do processo", desde que demonstrados os requisitos previstos nos incisos I a IV do art. 311.

Cassio Scarpinella Bueno, ${ }^{2}$ ao enfrentar essa lacuna, concluiu que:

sobre a presença dos elementos de tutela provisória para concessão do efeito suspensivo aos embargos à execução, cabe lembrar que a tutela provisória pode ser fundamentada na urgência e na evidência (art. 294, caput), não havendo razão nenhuma para destacar, aprioristicamente, que o embargante não possa trazer, com as adaptações cabíveis, a conhecimento do magistrado, nenhuma das hipóteses do art. 311 sobre a tutela de evidência.

Já Teresa Arruda Alvim Wambier et al. ${ }^{3}$ entendem que "a concessão do efeito suspensivo aos embargos pode se fundamentar na urgência ou na evidência, conforme o caso".

Essa possibilidade de que apenas os requisitos previstos no art. 311 do NCPC (preponderantemente ligados a bom direito e provas robustas) sejam demonstrados para atribuição do efeito suspensivo aos embargos de devedor é uma mudança

2 BUENO, Cassio Scarpinella. Novo Código de Processo Civil anotado. São Paulo: Saraiva, 2015. p. 526.

3 WAMBIER, Teresa Arruda Alvin et al. (Coord.). Primeiros comentários ao novo Código de Processo Civil: artigo por artigo. São Paulo: Revista dos Tribunais, 2015. p. 1301. 
de grande relevância, já que afasta a exigência de comprovação do receio de dano pelo executado, na hipótese de prosseguimento da execução fiscal.

\subsection{Efeitos da apelação em embargos à execução fiscal}

$\mathrm{Na}$ LEF não há qualquer previsão sobre o recurso cabível em face da sentença proferida em embargos de devedor nem sobre os efeitos que serão atribuídos ao recurso de apelação que em face dela pode ser interposto. Assim, estamos diante de clara lacuna completa da legislação especial que reclama, portanto, a aplicação subsidiária da norma geral (NCPC).

Analisando-se a regra geral, em face da sentença poderá ser interposto recurso de apelação (art. 1.009), que será recebido no efeito suspensivo, nos termos do art. 1.012 do NCPC, com algumas exceções. Ao ressalvar o efeito suspensivo automático, o $\int 1^{\circ}$ do mesmo dispositivo determina que "começa a produzir efeitos imediatamente após a sua publicação a sentença que [...] III - extingue sem resolução do mérito ou julga improcedentes os embargos do executado".

É evidente que a ausência de efeito suspensivo à apelação interposta em face de sentença que julga improcedentes os embargos à execução fiscal é deveras danosa ao executado, que passa a submeter-se ao risco de que o exequente busque a liquidação da garantia. Esse grave dano, contudo, pode ser mitigado, já que a legislação admite a concessão de tutela provisória com o propósito de evitar o prosseguimento da execução fiscal, ao permitir que a "eficácia da sentença seja suspensa pelo relator se o apelante demonstrar a probabilidade de provimento do recurso ou se, sendo relevante a fundamentação, houver risco de dano grave ou de difícil reparação" (art. 1.012, $\ 4^{\circ}$ ).

\subsection{A sucumbência nos embargos à execução fiscal}

Mais uma vez, silencia a LEF quanto à sucumbência aplicável em executivos fiscais e nos respectivos embargos de devedor, daí porque, sob esse aspecto, aplicam-se as disposições do NCPC.

O $\int 1^{\circ}$ do art. 85 do NCPC dispõe que "São devidos honorários advocatícios na reconvenção, no cumprimento de sentença, provisório ou definitivo, na execução, resistida ou não, e nos recursos interpostos, cumulativamente". Desse dispositivo podemos concluir que é possível a condenação cumulativa em execução fiscal e nos seus respectivos embargos de devedor.

Essa situação não é novidade e já foi inclusive analisada pelo STJ, que concluiu que "a condenação em honorários na execução fiscal não exclui a verba honorária 
devida nos embargos do devedor, pois este constitui verdadeira ação autônoma, observado o limite percentual de 20\% (art. 20, $₫ 3^{\circ}$, do CPC) na soma das duas verbas)" (Agravo Regimental no Agravo em REsp n. 632.630/MG, Rel. Min. Mauro Campbell Marques, $2^{\mathrm{a}}$ Turma, julgado em: 10 mar. 2015, DJe: 16 mar. 2015).

A grande inovação do NCPC ao contexto da sucumbência, na verdade, decorre do $\int 3^{\circ}$ do art. 85 , que estabelece percentuais mais objetivos e em menores faixas vinculados não mais ao valor da causa, mas ao benefício econômico almejado, nas ações em que figurar como parte a Fazenda Pública - o que inclui, evidentemente, as execuções fiscais e os respectivos embargos de devedor.

O CPC/73 previa em seu art. $20, \sqrt{\S} 4^{\circ}$ :

Nas causas de pequeno valor, nas de valor inestimável, naquelas em que não houver condenação ou for vencida a Fazenda Pública, e nas execuções, embargadas ou não, os honorários serão fixados consoante apreciação equitativa do juiz, atendidas as normas das alíneas a, b e c do parágrafo anterior. (grifo nosso)

Assim, se antes a legislação conferia ao magistrado grande liberdade para definir o percentual de honorários advocatícios a serem cobrados da Fazenda Pública, o NCPC passou a estabelecer regra isonômica que impõe a fixação de honorários seguindo os mesmos parâmetros em faixas percentuais variáveis conforme o valor envolvido na demanda, seja quando a Fazenda Pública for vencida, seja quando for vencedora.

A nosso ver, além de trazer critério isonômico para fixação de sucumbência, a novel legislação é positiva, pois permite aos litigantes (contribuintes) identificar de forma mais objetiva o risco financeiro relacionado ao ajuizamento de determinada ação judicial provocado por eventual julgamento final desfavorável. Isso porque, se pelo regime do $\mathrm{CPC} / 73$ o contribuinte estava sujeito à condenação de honorários que poderiam ser fixados em até $20 \%$ do valor em discussão, pela nova sistemática, a parte estará sujeita a novas faixas que poderão dar ensejo a uma condenação que variará de $1 \%$ a $3 \%$ do valor discutido (art. 85 , inciso V).

\subsection{Os encargos da dívida ativa}

Diante desses novos limites de sucumbência fixados pela legislação, é necessário que se faça uma reflexão sobre a possibilidade de as Fazendas Públicas continuarem exigindo os encargos da inscrição em dívida ativa em percentuais fixos que desconsiderem por completo o valor em execução. Entendemos que essa conduta 
não mais se adequa à legislação hoje em vigor. Com efeito, a nosso ver, o $\int 3^{\circ}$ do art. 85 do NCPC, ao instituir faixas de parâmetro para fixação dos honorários, revogou o chamado "encargo legal", previsto no art. $1^{\circ}$ do Decreto-Lei $n$. 1.025/1969, que autoriza a Fazenda Nacional a cobrar "taxa, no total de 20\% (vinte por cento), paga pelo executado, a ser recolhida aos cofres públicos, como renda da União".

Essa conclusão decorre da natureza jurídica do "encargo legal", que foi analisado pelo STJ, ${ }^{4}$ o qual entendeu que ele substitui a verba honorária a que teria direito a União quando saísse vencedora em ações que têm por objeto débito inscrito em dívida ativa. Esse entendimento tem origem na Súmula 168 do antigo Tribunal Federal de Recursos: “O encargo de 20\%, do Decreto-Lei 1.025, de 1969, é sempre devido nas execuções fiscais da União e substitui, nos embargos, a condenação do devedor em honorários advocatícios o encargo legal cobrado pela Fazenda Nacional por ocasião".

Ora, se o encargo de 20\% do Decreto-Lei n. 1.025/1969 tem verdadeira natureza de honorários advocatícios e o NCPC determina que nas demandas envolvendo a Fazenda Pública os honorários de sucumbência deverão ser fixados de acordo com as faixas previstas no $\int 3^{\circ}$ do art. 85 , as quais preveem na maioria das vezes a exigência de honorários em patamar inferior a $20 \%$, evidentemente estamos diante de normas que conflitam entre si. Nesse caso, não estamos diante de conflito entre a aplicação subsidiária ou supletiva do NCPC à LEF, mas de duas normas jurídicas distintas tratando de uma mesma situação: os percentuais de sucumbência aos quais faz jus a Fazenda Nacional. Deveras, a execução fiscal ajuizada pela Fazenda Nacional é uma demanda envolvendo a Fazenda Pública, que atrai a regra do art. $85, \mathbb{S} 3^{\circ}$, do NCPC.

Diante dessa "antinomia jurídica", o artigo $1^{\circ}, \int 1^{\circ}$, do Decreto-Lei n. 4.657/1942 (Lei de Introdução às Normas do Direito Brasileiro) determina a aplicação do critério cronológico:" $\int 1^{\circ}$ A lei posterior revoga a anterior quando expressamente o declare, quando seja com ela incompatível ou quando regule inteiramente a matéria de que tratava a lei anterior". Em outras palavras, tratando ambas as leis de honorários advocatícios sucumbenciais em causas envolvendo a Fazenda Nacional, de rigor seria a aplicação da lei posterior, qual seja, o NCPC.

4 REsp n. 1143320/RS, Rel. Min. Luiz Fux, 1ª Seção, julgado em: 12 maio 2010, DJe: 21 maio 2010, julgado sob a sistemática dos recursos repetitivos (art. 543-C do CPC/73). 
Mas não é só isso: a exigência de encargo legal na faixa de $20 \%$ gera situação claramente anti-isonômica na medida em que assegura à Fazenda Pública, nos casos em que venha a lograr êxito em execuções e ações anulatórias de valores mais elevados, honorários cerca de dez vezes maiores que os devidos ao particular na hipótese de a Fazenda ser vencida, a depender do valor envolvido.

Da comparação entre a potencial sucumbência aplicável sob a égide do CPC/73 e o encargo legal previsto pelo Decreto-Lei n. 1.025/1969, não se identificava violação ao princípio da isonomia, pois a sucumbência devida ao advogado do contribuinte na hipótese de o débito ser cancelado poderia chegar aos mesmos 20\% do encargo legal. A nova legislação processual, contudo, editada com o expresso propósito de valorizar e observar preceitos constitucionais, ao estabelecer faixas de honorários aplicáveis igualmente a ambas as partes envolvidas no litígio bem denota que o tratamento deve ser equivalente. Logo, não há como se admitir a imposição dos encargos legais na razão de $20 \%$ quando os honorários do advogado do contribuinte atingiriam percentual muito inferior a esse.

Por conta disso, independentemente do critério que se utilize para aplicação dos percentuais de condenação em sucumbência, seja o cronológico, seja a adequação ao texto constitucional, os encargos previstos pelo Decreto-Lei n. 1.025/1969 devem respeitar as novas faixas percentuais previstas pelo NCPC, o que significa encargos máximos de 3\% para dívidas de valor expressivo.

Situação ainda mais grave que a das execuções fiscais propostas pelo fisco federal, nas quais a manutenção dos encargos legais no patamar de $20 \%$ pode ser controversa, nas execuções fiscais estaduais e municipais a inclusão de encargos correspondentes a 20\% do débito acontece sem qualquer previsão normativa, sob o pretexto de se tratar de antecipação dos honorários que seriam devidos na execução do débito. Nesses casos, a redução dos honorários para adequá-los aos percentuais previstos pelo art. $85, \S 3^{\circ}$, do NCPC é medida que se impõe de forma ainda mais clara.

\section{CONSIDERAÇÕES FINAIS}

Por meio do presente trabalho, foi possível notar que o NCCP, editado com o propósito de dar ênfase às garantias constitucionais do processo civil, aplica-se subsidiariamente ao rito das execuções fiscais e dos respectivos embargos de devedor. A aplicação subsidiária de suas diretrizes deve ocorrer sempre que a LEF não tratar do assunto e desde que não seja com ela incompatível, já que não se admite que lei geral posterior revogue lei especial anterior. 
A nosso ver, para a aplicação subsidiária do NCPC ao rito das execuções fiscais, é necessário que a lacuna da lei especial seja completa, afastando-se assim a aplicação da norma geral nas situações em que a LEF trate apenas parcialmente do tema.

Por derradeiro, parece-nos que o impacto mais relevante do NCPC ao processo de execução fiscal está ligado à aplicação dos novos critérios de sucumbência e aos efeitos deles decorrentes aos encargos da inscrição em dívida ativa. Com efeito, a inclusão dos encargos da inscrição em dívida ativa para fazer frente a eventual condenação em sucumbência em patamar fixo de $20 \%$, desconsiderando por completo o valor inscrito em dívida ativa, além de contrariar o NCPC impõe situação anti-isonômica entre os advogados do contribuinte e da Fazenda Pública.

A conclusão a que se chega é que, para o NCPC dar a efetividade que busca à $\mathrm{CF}$, essa situação deve ser levada ao judiciário, que certamente ajustará os indigitados encargos da inscrição em dívida ativa aos patamares adequados ao valor em execução. 
